\title{
ANÁLISE DA LOGÍSTICA INTERNA DAS VINÍCOLAS DOS VALES DA UVA GOETHE
}

DOI: http://dx.doi.org/10.18616/pidi03

Michele Domingos Schneider - UNESC

E-mail: michele.schneider@unesc.net Adriana Carvalho Pinto Vieira - UNESC

E-mail: dricpvieira@gmail.com Andréa Leda Ramos de Oliveira - UNICAMP E-mail: andrea.oliveira@feagri.unicam.br 


\section{INTRODUÇÃO}

A cidade de Urussanga, localizada no extremo sul do estado de Santa Catarina, é conhecida no cenário estadual e nacional pela produção e qualidade de seu vinho (MAESTRELLI, 2011). A uva Goethe chegou a Urussanga junto com os primeiros colonizadores italianos, por volta da década de 1878, uma das poucas espécies que se adaptou ao clima e ao solo da região. Ao longo da história, o cultivo da uva e a produção do vinho Goethe passaram por diversos momentos, desde a produção maciça após a adaptação da espécie, o quase abandono da lavoura no governo de Getúlio, o ressurgimento em 1970 e a fundação da PROGOETHE até o movimento pelo reconhecimento da IPVUG (VELLOSO, 2008).

A uva Goethe é uma espécie única, sem relações com as demais variedades de uvas catalogadas, fato esse confirmado pelos relatos de Schuck et. al. (2010). As peculiaridades da variedade da uva Goethe impulsionam o movimento pela Indicação Geográfica que surge a partir de 2005, com a criação da Associação dos Produtores da Uva e do Vinho Goethe - PROGOETHE. A PROGOETHE possui seu quadro de associados formado por produtores de uva e produtores de vinho, os quais constituem unidades de produção familiares (VELLOSO, 2008). Atualmente, a abrangência da PROGOETHE compreende oito municípios situados na região sul do estado de Santa Catarina, contando em seu quadro com cinco vinícolas, quatro produtores de vinho artesanal e três produtores de uva (ASSOCIAÇÃO DOS PRODUTORES DA UVA E DO VINHO GOETHE, s.d.).

O movimento da Indicação Geográfica, apesar de recente, já apresenta resultados para a produção de uvas e vinho na região delimitada. Nesse curto espaço de tempo em que a IPVUG esteve estabelecida, houve um aumento na produção de uvas Goethe na cidade de Urussanga, e o valor agregado do produto também foi perceptível, de forma que, com a maior visibilidade do produto e da IG, a tendência foi que os negócios nas vinícolas cresceram e se expandiram, fazendo com que diversos aspectos da gestão desses negócios fossem repensados.

Com o movimento estabelecido para a busca da Indicação Geográfica e a criação da PROGOETHE, as vinícolas buscaram adaptar seus processos de produção para a obtenção do selo de certificação dos produtos. Essas mudanças passaram pela compreensão das condições e da identificação dos fatores determinantes no aprimoramento da logística interna, com vistas a atender às 
demandas oriundas da ampliação das vendas, da redução dos custos logísticos inerentes aos processos internos e da melhoria dos níveis de atendimento aos clientes.

As vinícolas associadas à PROGOETHE compreendem pequenas propriedades e empresas familiares, de forma que é necessário e fundamental realizar investigações de como estão estruturados os processos logísticos internos das organizações (ROMEIRO, 2002). A partir desse contexto, o presente capítulo foi estruturado com o objetivo de avaliar as estruturas logísticas disponíveis, bem como as perspectivas de incremento nas operações logísticas das empresas associadas à PROGOETHE.

\section{LOGÍSTICA}

A concepção da logística e de suas aplicações vem se solidificando no campo empresarial como consequência da busca constante por eficiência e competitividade nos negócios. Isso fez com que as organizações passassem a se concentrar não apenas na otimização de seus processos internos, visando à redução de custos e à melhoria nos serviços oferecidos, mas também na otimização dos processos externos, aprimorando as relações com fornecedores e clientes.

Essa visão contemporânea de logística é o que conhecemos por Supply Chain Management ou Gestão da Cadeia de Suprimentos. Para o Council of Supply Chain Management Professional (GIBSON; MENTZER; COOK, 2005), a Gestão da Cadeia de Suprimentos engloba o planejamento e o gerenciamento de todas as atividades envolvidas na aquisição, no fornecimento e na transformação e em todas as atividades de gerenciamento da logística. Isso inclui a coordenação e a colaboração dos membros da cadeia, que podem ser fornecedores, intermediários, prestadores de serviços e clientes. Em essência, a Gestão da Cadeia de Suprimentos integra oferta e demanda dentro e entre empresas.

Quando a competição no mundo dos negócios era menor, as incertezas de mercado eram mais controláveis e os ciclos dos produtos eram mais longos, a busca por um diferencial competitivo pelas organizações se dava por meio da gestão eficiente de atividades isoladas, com compras, transportes, ar- 
mazenagem, fabricação, manuseio de materiais e distribuição. Essas atividades eram desempenhadas por setores isolados, cujo desempenho era medido por indicadores como custos de transportes mais baixos, menores estoques e compras ao menor preço (FIGUEIREDO; ARKADER, 2011).

Já no período, esse cenário mudou. Hoje, os mercados estão cada vez mais globalizados e dinâmicos, e os consumidores cada vez mais exigentes, buscando produtos diferenciados. Para satisfazer a esses anseios, prolifera-se uma quantidade de novos produtos, com ciclos de vida bem mais curtos. Dessa forma, a coordenação da gestão de materiais, da produção e da distribuição passou a dar respostas mais eficazes para dar conta das novas demandas geradas por tais produtos de forma a garantir o sucesso dos negócios. Nessa perspectiva, surge o conceito de Logística Integrada. Isso significou considerar como componentes de um sistema todas as atividades de movimentação e armazenagem que facilitam o fluxo de produtos desde o ponto de aquisição dos materiais até o ponto de consumo final, considerando ainda os fluxos de informação (FIGUEIREDO; ARKADER, 2011).

A sequência natural desse processo é o desenvolvimento do conceito de Gestão da Cadeia de Suprimentos, que é uma evolução natural da Logística Integrada. Uma vez que a Logística Integrada representa uma integração interna das atividades das organizações, a Gestão da Cadeia de Suprimentos representa sua integração externa, pois estende a coordenação dos fluxos de materiais e de informações aos fornecedores e ao cliente final.

No gerenciamento da cadeia de suprimentos, as organizações envolvidas cooperam mutuamente por meio da integração das informações (COSTA; MACADA, 2009), com a finalidade de alavancarem seu posicionamento estratégico, com vistas à eficiência das operações, sejam elas individuais ou coletivas (BOWERSOX; CLOSS; COOPER, 2006), surgindo questões relacionadas às interfaces do relacionamento entre os membros da cadeia de suprimentos (ZANQUETTO FILHO; FEARNE; PIZZOLATO, 2006).

O objetivo da cadeia de suprimentos é agregar e maximizar o valor gerado. A concepção de valor em cadeia de suprimentos é a diferença entre os custos efetivos de produção e a distribuição e o valor monetário pago pelo cliente. Em muitos casos, esse valor gerado é assemelhado à lucratividade da cadeia (CHOPRA; MEINDL, 2011). O Gerenciamento da Cadeia de Suprimentos (GCS) requer transparência nos processos de avaliação de desempenho entre membros e processos (ZANQUETTO FILHO; FEARNE; PIZZOLATO, 2006). 


\section{ATIVIDADES LOGÍSTICAS E LOGÍSTICA INTERNA}

As atividades logísticas variam de empresa para empresa, de acordo com a concepção da cadeia de suprimentos, os componentes, os membros da cadeia e os objetivos (GUARNIERI et al., 2006). Porém, independentemente da concepção e da configuração da cadeia de suprimentos, existem atividades comuns que são as atividades principais da logística ou atividades-chave e atividades de suporte (BALLOU, 2006).

As atividades logísticas relacionam-se diretamente na formulação e na concretização das estratégias da organização (WANKE, 2003); dessa forma, devem estar alinhadas ao planejamento organizacional (TAVARES, 2005). O alinhamento das estratégias às atividades logísticas pode permitir que a organização alcance os melhores resultados e o estabelecimento de diferenciais competitivos (MORAIS, 2015).

Nesse contexto, têm-se as atividades-chave do processo logístico, que são atividades primárias para o atendimento dos objetivos logísticos (POZO, 2002), consideradas atividades críticas para a efetivação das estratégias (CHRISTOPHER, 1999; NOVAES, 2001; BOWERSOX et al., 1992; KOBAYASHI, 2000; FLEURY, 2000), as quais assumem relevância para a cadeia, uma vez que representam custos significativos para o seu gerenciamento (BALLOU, 2006).

Dentre as atividades-chave, podem ser citados a padronização dos serviços ao cliente (GUARNIERI et al., 2006), o transporte (ZANQUETTO FILHO; FEARNE; PIZZOLATO, 2006), a manutenção dos estoques (PARDINI; MATUCK, 2012) e o processamento dos pedidos (BRONZO, 2004).

Já as atividades de suporte são aquelas que compõem o processo logístico, também chamadas de atividades de apoio, pois auxiliam na consolidação das estratégias, nos planejamentos e na operação logística (ZANQUETTO FILHO; FEARNE; PIZZOLATO, 2006). Dentre as atividades de suporte estão a armazenagem, o manuseio de materiais, as compras, a embalagem de proteção, a cooperação com a produção e a manutenção de informação (BALLOU, 2006).

$\mathrm{O}$ gerenciamento das atividades logísticas, sejam elas as atividades-chave ou as atividades de suporte, permite que a organização possa monitorar o desempenho logístico da cadeia de suprimentos (GOMES; RIBEIRO, 2004). 


\section{METODOLOGIA}

A presente pesquisa buscou avaliar as estruturas logísticas disponíveis e as perspectivas de melhoria na logística interna das empresas associadas à PROGOETHE. Para tanto, foi utilizado o referencial metodológico desenvolvido por Moura (2008), que propõe um conjunto de questões para a realização da checklist da logística interna. Além disso, a pesquisa também se utilizou de técnicas de entrevista em profundidade e observação não participante.

Do instrumento de Moura (2008) foram selecionadas 7 (sete) seções, em função da extensão do instrumento e no sentido de abordar os pontos mais críticos na gestão da logística interna das vinícolas. As seções abordadas na pesquisa foram: logística, recebimento, almoxarifado, movimentação e estocagem em processo, embalagem, armazenagem de produtos acabados, expedição. Cada seção conta com 20 questões, que apresentam as possibilidades de respostas ("sim", "não" e "em parte"). O somatório das respostas "sim" permitiu a análise e a avaliação do processo avaliado. Os resultados compreendidos entre 16 a 20 apontam para um excelente processo; de 10 a 15, o processo necessita de melhorias, e, abaixo de 10, esse é um fator crítico para a operação logística e precisa ser reestruturado.

\section{APRESENTAÇÃO DOS RESULTADOS}

A logística interna das vinícolas obedece a fluxos semelhantes, os quais são apresentados na Figura 1.

Figura 1 - Fluxograma da Logística Interna das Vinícolas

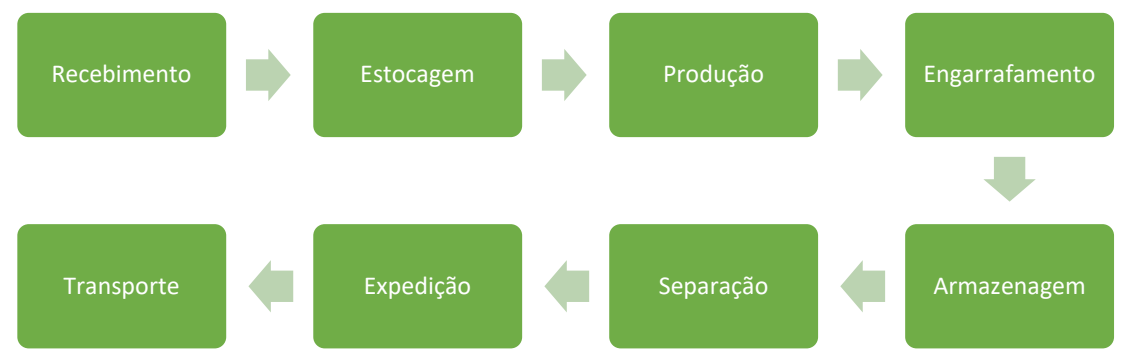

Fonte: Dados da Pesquisa. 
As matérias-primas e os insumos são recebidos, conferidos e estocados em locais de estocagem ou naqueles que ficam próximo aos pontos de consumo. Posteriormente, são direcionados à produção de vinho. Quando o vinho fica pronto, de acordo com a demanda, ele é engarrafado e rotulado. As garrafas rotuladas são direcionadas em caixas de papelão para o armazém de produtos acabados e permanecem nesse espaço até o momento da expedição, momento no qual os produtos são separados de acordo com os pedidos de venda, expedidos e transportados até os clientes.

\section{BLOCO LOGÍSTICA}

A Figura 2 ilustra os resultados da pontuação geral das cinco vinícolas referentes ao Bloco Logística.

Figura 2 - Pontuação Geral do Bloco Logística

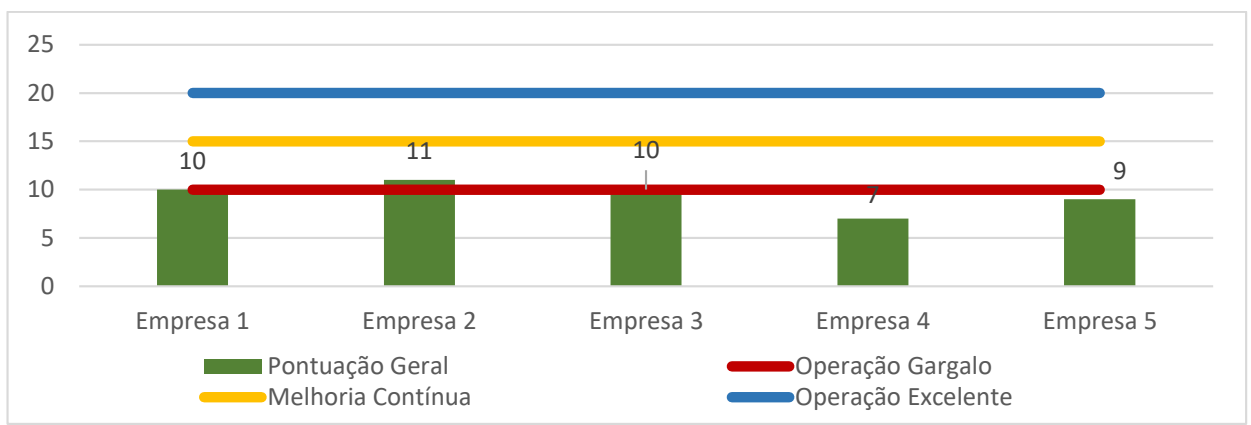

Fonte: Dados da Pesquisa.

Em uma análise geral dos resultados do Bloco "Logística", é possível perceber uma discrepância nos resultados no bloco por parte da Empresa 01. Ela obteve apenas 2 (dois) pontos, enquanto as demais empresas obtiveram entre 6 (seis) e 9 (nove) pontos.

Observou-se que nas empresas estudadas não existem objetivos claramente definidos, sendo necessária a realização de um diagnóstico logístico, com vistas à identificação das necessidades de prestação de serviços por parte do cliente. Esse diagnóstico passa pela identificação dos prazos de entrega, dos níveis de serviço de atendimento, do cumprimento dos pedidos, das frequências de entrega, dentre outros (MOURA, 2008). 
De posse das informações do diagnóstico, as empresas terão subsídios para definir os indicadores e as metas de desempenho dos custos e serviços logísticos. Os indicadores e metas são importantes para a elaboração das estratégias empresariais e dos planos de ação e devem ser acompanhados constantemente para a identificação de possíveis desvios e distorções no planejamento.

É necessário, também, que as empresas definam uma estrutura de custos por meio da qual seja possível o acompanhamento, considerando os recursos tecnológicos e informacionais de que a empresa dispõe. E que, por meio dessa estrutura definida, procedam o acompanhamento contínuo dos custos.

Faz-se necessário, também, o acompanhamento do desempenho dos concorrentes, no sentido de monitorar as estratégias dos concorrentes e a efetividade de suas próprias estratégias. Definidas as estratégias logísticas da organização, é importante elaborar um planejamento logístico que envolva informações e planejamento de marketing e vendas para levantar as necessidades de recursos humanos, financeiros, tecnológicos e os materiais necessários para atingir os objetivos da empresa.

\section{BLOCO RECEBIMENTO}

O recebimento é o início dos processos da logística interna. Em muitas empresas, ele é feito de forma manual, sem planejamento, o que ocasiona as ineficiências nos processos seguintes, como a movimentação e a armazenagem (MOURA, 2008).

Figura 3 - Pontuação Geral Bloco Recebimento

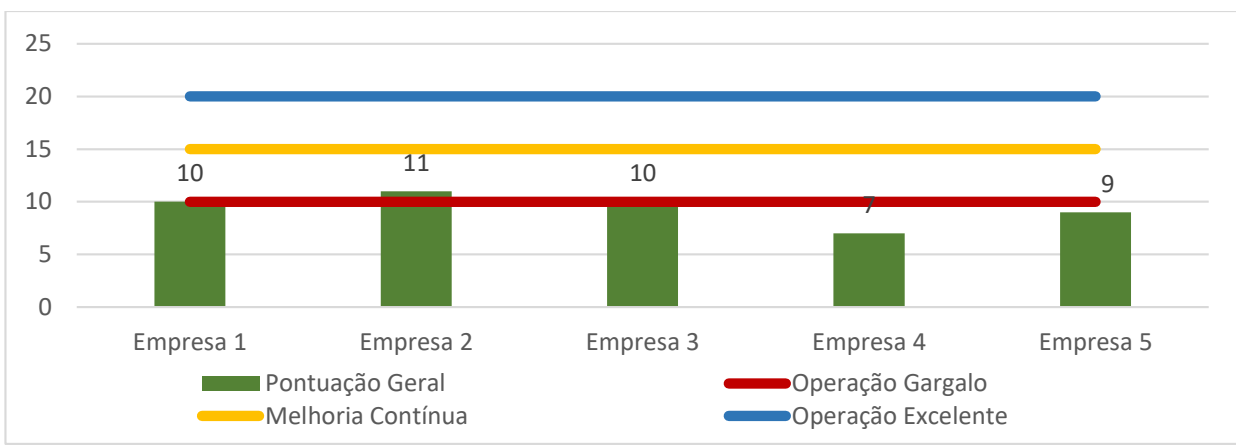

Fonte: Dados da Pesquisa. 
O "Recebimento" é considerado uma atividade crítica para as Empresas 01 e 05, que obtiveram 5 (cinco) e 7 (sete) pontos respectivamente. Já para as Empresas 02, 03 e 04, por obterem pontuações entre 10 (dez) e 11 (onze) pontos, necessitam de melhorias contínuas em todas as atividades que envolvem o recebimento.

No recebimento, é possível perceber, por meio das entrevistas realizadas, que as vinícolas não apresentam certezas com relação aos horários de recebimento dos produtos comprados. As transportadoras e fornecedores, normalmente, não cumprem os horários estabelecidos para a descarga.

Os volumes recebidos são baixos, de forma que não são registradas filas de caminhões no recebimento. Porém, nos momentos em que isso ocorre, o recebimento é rápido. Apenas as Empresas 02, 03 e 04 possuem pátio para o estacionamento de caminhões. Apenas a Empresa 03 possui rampas e plataformas suficientes para receber, simultaneamente, 2 (dois) caminhões.

Todas as empresas conferem os volumes dos produtos antes da descarga. Apenas a Empresa 05 recebe os produtos em um recebimento central. As demais vinícolas possuem pelo menos 2 (dois) pontos de recebimento. Após o recebimento, a Empresa 04 estoca os materiais no ponto de uso. As Empresas 02, 03 e 05 estocam alguns produtos próximo ao ponto de uso e a Empresa 01 possui um almoxarifado central.

De maneira geral, as empresas não recebem os produtos com identificação própria e também não são utilizados códigos de barras ou radiofrequência no recebimento. Com relação aos equipamentos utilizados para o recebimento, apenas as Empresas 03 e 04 possuem empilhadeiras manuais. As Empresas 02 e 05 possuem paleteiras e carrinhos para o recebimento, e a Empresa 01 dispõe apenas de carrinhos para a atividade.

Todas as empresas recebem produtos em paletes, embora a ocorrência seja registrada apenas para as garrafas de vinho. Nesse caso, a Empresa 01 aluga uma empilhadeira para a descarga e é a única empresa que considera não possuir os equipamentos adequados para o recebimento.

Para os produtos recebidos em unidades inferiores aos paletes, o recebimento é rápido em todas as vinícolas, muito pelo fato de o volume recebido ser pequeno. Os produtos são rapidamente direcionados aos pontos de estocagem.

Como sugestões para aprimorar a atividade de recebimento e considerando um aumento no volume de produção da organização, de acordo com 
Moura (2008), será necessário o estudo do fluxo dos materiais na área de recebimento e de deslocamento para a área de armazenagem, tomando-se como base os tipos de produtos, as características das cargas recebidas, o número de recebimentos por período, os métodos de descarga, a necessidade de equipamentos de movimentação, a mão de obra necessária e o tempo necessário para descarga.

Os processos de conferências no recebimento são fundamentais para a certificação do correto recebimento e posterior contribuição para a acuracidade dos estoques. Moura (2008) sugere também uma aproximação com fornecedores e transportados, no sentido de definir horários para as entregas. Dessa forma, é possível organizar a área e os recursos necessários para o recebimento.

\section{BLOCO ESTOCAGEM}

A estocagem é a atividade de guarda dos materiais até que sejam solicitados para o processo produtivo. A atividade pode apresentar alguns problemas e ineficiências no processo, gerando atrasos e imprecisão nos inventários. Assim, a atividade de estocagem precisa ser planejada, permitindo o máximo aproveitamento dos espaços (MOURA, 2008).

Figura 4 - Pontuação Geral Bloco Estocagem

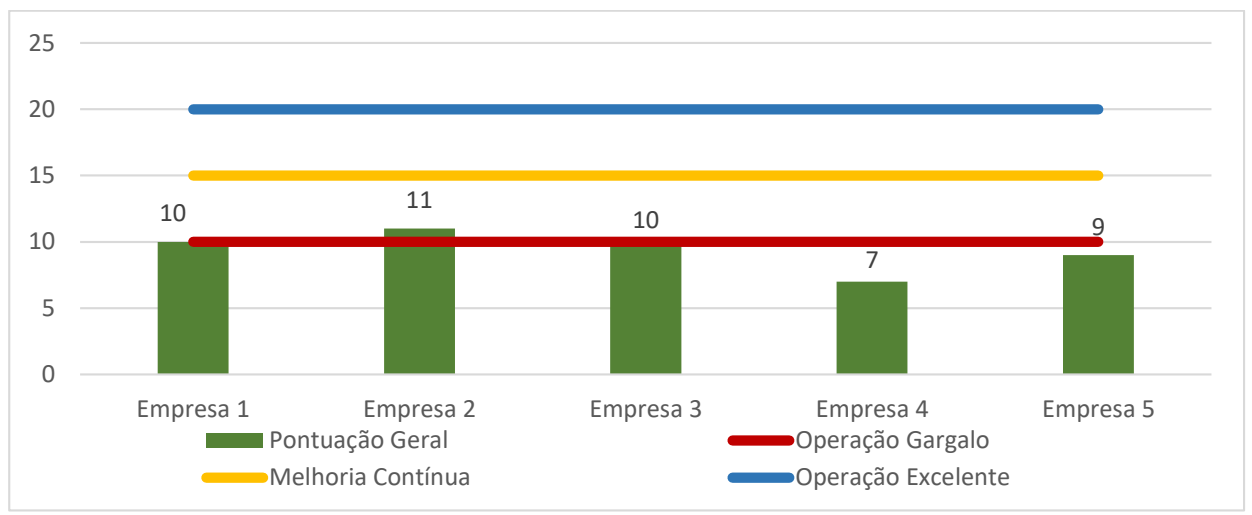

Fonte: Dados da Pesquisa.

No Bloco "Estocagem", observam-se diferenças significativas entre as 5 (cinco) vinícolas. As Empresas 03 e 04 obtiveram 6 (seis) pontos cada uma; a 
empresa 01, 7 (sete) pontos, e a Empresa 5 obteve 9 (nove) pontos. Para essas 4 (quatro) empresas, a atividade estocagem é considerada por Moura (2008) uma atividade crítica, provável gargalo, e requer uma análise e redesenho do processo urgente. Apenas a Empresa 02 obteve 12 (doze) pontos, mesmo assim, ela precisa desenvolver melhorias contínuas na atividade.

$\mathrm{Na}$ questão da armazenagem, as empresas pesquisadas não utilizam sistemas de alocação e endereçamento de materiais informatizados e também não são utilizados sistemas de códigos de barras e radiofrequência. Os equipamentos de movimentação são adequados para a movimentação dos itens em paletes, mas quanto aos itens em caixas abertas, exceto para a Empresa 03.

Os procedimentos para a localização dos materiais nas áreas de armazenagem é um ponto crítico para as 5 (cinco) vinícolas, de forma que apenas a Empresa 05 julga ser fácil qualquer pessoa localizar itens em seu armazém. As Empresas 01, 02 e 04 consideram difícil a localização dos itens, embora os itens sejam facilmente acessados.

O layout é considerado ordenado e com bom fluxo apenas para as Empresas 01 e 02. As empresas 03, 04 e 05 consideram relativamente ordenados os seus layouts. As saídas de estoques do armazém para a produção não são documentadas em nenhuma das vinícolas.

No sentido de aperfeiçoar a estocagem, Moura (2008) sugere a utilização de paletes ou contenedores o máximo possível e com tamanhos padronizados, além de manter os corredores limpos e desimpedidos de materiais que possam dificultar o acesso aos produtos e às áreas de armazenagem.

Moura (2008) também sugere a utilização de controles de estoques, a alocação dos produtos de acordo com o tamanho de cada item e o estabelecimento de inventários cíclicos ou periódicos para a redução das perdas com a estocagem e a utilização da classificação $A B C$ dos estoques.

A sinalização dos espaços de armazenagem e a elaboração de sistema de alocação dos materiais surgem como alternativa importante para facilitar a localização rápida dos produtos estocados por qualquer funcionário (MOURA, 2008). 


\section{BLOCO MOVIMENTAÇÃO E ESTOCAGEM EM PROCESSO}

Para Moura (2008), a "Movimentação e Estocagem em Processo" é outra atividade que não agrega valor e que, quando mal planejada, pode acarretar em atrasos no processo produtivo.

Figura 5 - Pontuação Geral Bloco Movimentação

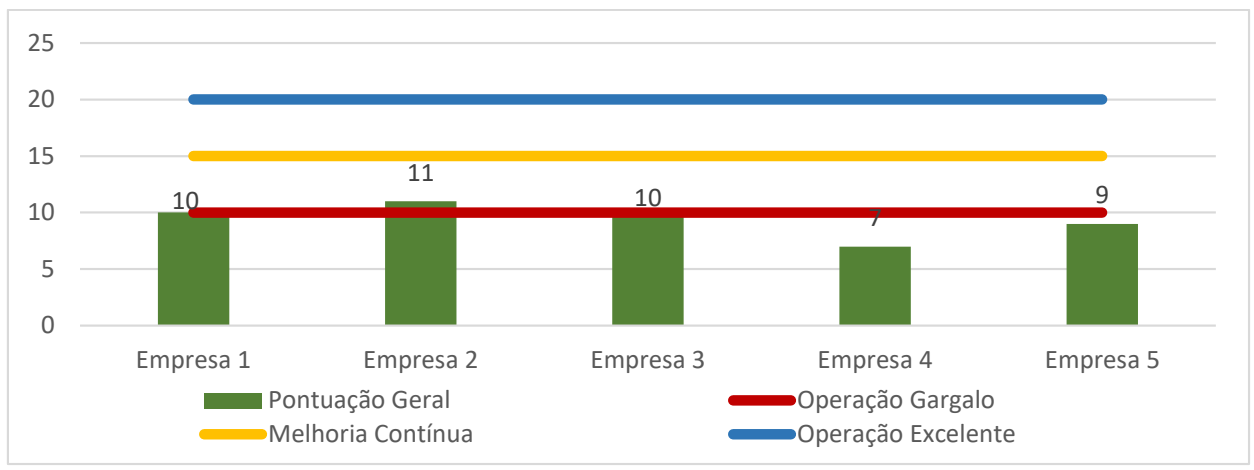

Fonte: Dados da Pesquisa.

A atividade de "Movimentação e Estocagem em Processo" é considerada crítica para as Empresas 01, 03 e 04, devido à pontuação obtida, ou seja, 08 (oito), 07 (sete) e 9 (nove), respectivamente. Para essas empresas, é necessário o redesenho dos processos que envolvem a atividade. As Empresas $02 \mathrm{e}$ 05, com pontuações 13 (treze) e 10 (dez), respectivamente, encontram-se em melhor situação na atividade, mas necessitam de melhoria contínua para não comprometerem a logística interna.

O fluxo dos materiais nas vinícolas segue o fluxo do processo de produção. Na maioria das empresas, esse fluxo de material foi planejado, e a estocagem de produtos no ponto de uso (Empresas 01, 02 e 04) é uma prática. Os corredores não são demarcados, e as distâncias percorridas, em grande parte, são mínimas entre as operações.

O layout proporciona fluxos otimizados, porém, nas Empresas 01 e 04, existe retrocesso de material no processo produtivo. Todas as empresas pesquisadas consideram fácil o acompanhamento do fluxo de materiais no processo, mas nenhuma delas faz a estimativa dos tempos padrões para a movimentação dos produtos nem dos indicadores de desempenho na movimentação, bem como não possuem métodos formais de prevenção de acidentes. 
Com o objetivo de otimizar as atividades de "Movimentação e Estocagem em Processo", é importante que a organização avalie as atividades e compreenda o fluxo de materiais, reduzindo gradativamente os estoques de produtos no processo, de acordo com o que aponta Moura (2008).

Nesse sentido, é fundamental a mecanização da movimentação de materiais, objetivando a mínima manipulação dos produtos, a mínima distância percorrida, utilizando equipamentos mecanizados ou, pelo menos, a máxima redução possível de operações manuais (MOURA, 2008). Outra alternativa a ser considerada, sugerida por Moura (2008), é a estocagem dos materiais no ponto de uso, pois otimiza a movimentação e reduz custos.

\section{BLOCO EMBALAGEM}

A embalagem, em muitas empresas, é negligenciada e tratada como aspecto secundário do negócio. Porém, em termos de embalagens para a pesquisa, foi considerado todo o sistema de recursos necessários para proteger o produto e permitir o acesso aos consumidores, com fundamento no que dispõe Moura (2008).

Para fins de esclarecimentos, consideraram-se embalagens no estudo as garrafas utilizadas para envazar o vinho e as caixas utilizadas para embalá-lo, unitizar as cargas, armazenagem e transporte do produto acabado.

Figura 6 - Pontuação Geral Bloco Embalagem

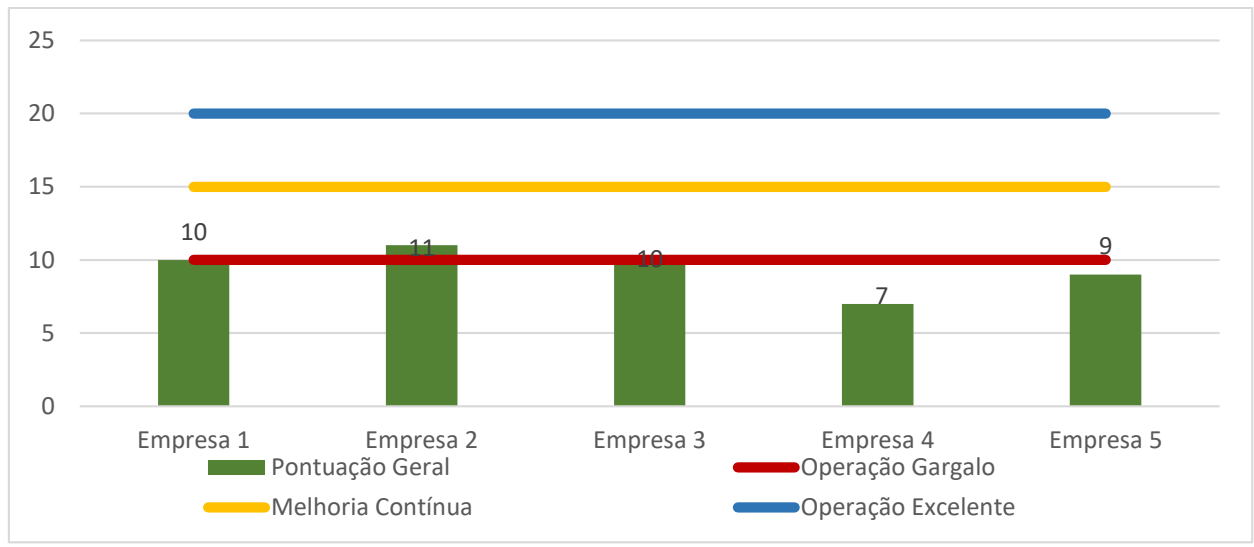

Fonte: Dados da Pesquisa. 
No Bloco "Embalagem", a atividade foi considerada crítica para as Empresas 02, 03 e 04 e requer atenção especial das Empresas 01 e 05. Todas as empresas, ao solicitarem as embalagens, fazem especificações próprias aos fornecedores, como impressão de logomarca, endereço, nome da empresa, tipo de vinho, entre outras. Apenas as Empresas 01 e 05 as reaproveitam no processo produtivo, enquanto a Empresa 05 reutiliza até mesmo as garrafas.

Os fornecedores de embalagens conseguem atender aos pedidos de pequenas quantidades, porém com custos proporcionais aos volumes pedidos. No ato do recebimento, não é praticada a troca de embalagens em nenhuma das empresas pesquisadas.

As embalagens atendem à legislação em vigor. No entanto, vale destacar que, em termos de legislação, a única exigência é com relação às garrafas de vinho e espumante Goethe, que têm suas especificações reguladas no Manual de Uso proposto pelo Conselho Regulador da Indicação de Procedência dos Vales da Uva Goethe.

Apenas a Empresa 01 não desenvolve embalagens especiais para os clientes; as demais atendem a essas necessidades, principalmente com o desenvolvimento de rótulos personalizados, frequentemente utilizados em épocas festivas. Segundo os entrevistados, as embalagens são reutilizáveis, embora essa não seja uma prática nas vinícolas, e ajudam a promover o produto. Elas foram desenvolvidas para proteger o seu conteúdo contra as adversidades ambientais, principalmente em se tratando de garrafas.

No aspecto Embalagem, as empresas precisam estabelecer uma parceria com os fornecedores para o desenvolvimento de embalagens que primem pela preservação dos produtos e permitam o máximo empilhamento e transporte, assim como verificar continuamente se estão sendo aplicadas novas possibilidade de embalagens que possam baratear os custos, sem descuidar da qualidade e da preservação dos produtos.

\section{BLOCO ARMAZENAGEM}

A função "Armazenagem" compreende a guarda dos produtos acabados para posterior envio aos clientes e atendimento à demanda (MOURA, 2008). No caso das vinícolas, o processo é empurrado e tem formação de estoques. $\mathrm{Na}$ maioria das empresas, os vinhos são engarrafados de acordo com a demanda. 
Figura 7 - Pontuação Geral Bloco Armazenagem

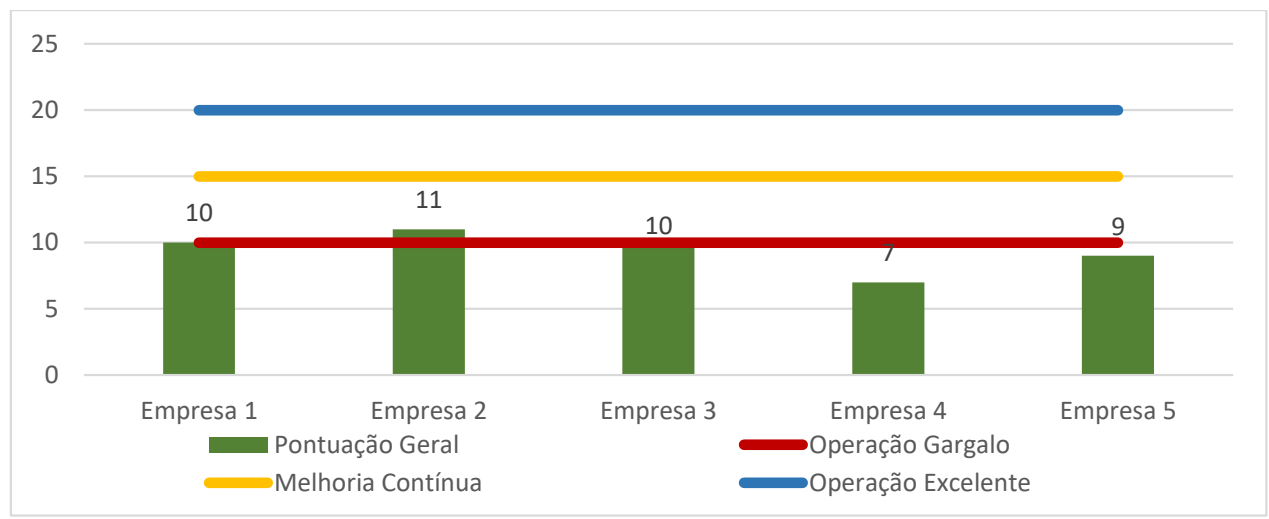

Fonte: Dados da Pesquisa.

A Armazenagem é uma das atividades que apresenta maiores pontuações. Em nenhuma das empresas pesquisadas, ela é atividade crítica. Para as Empresas 01, 02, 04 e 05, a armazenagem necessita de melhoria contínua, já para a Empresa 03 ela é excelente.

As instalações dessas empresas são adequadas para a armazenagem do vinho, sendo que algumas vinícolas têm as paredes de pedra, o que torna o ambiente climatizado naturalmente. No entanto, nenhuma delas possui sistemas adequados de controle de estoques. Para isso, a Empresa 04 utiliza planilhas de Excel $^{\circledR}$, enquanto a Empresa 05 dispõe de um sistema de emissão de nota fiscal com a função de controle, o qual não é utilizado. O sistema de estocagem facilita a separação dos produtos em quase todas as empresas. Apenas a Empresa 04 relatou relativa facilidade em função de questões relacionadas à estrutura física.

As Empresas foram unânimes em admitir que suas instalações, layouts e fluxos atendem aos objetivos organizacionais. Elas consideram o depósito uma área tão importante quanto as demais. O layout foi concebido na construção do prédio nas Empresas 02 e 03.

Quanto aos atendimentos de pedidos urgentes, as Empresas 01, 02 e 05 conseguem atender a pedidos em caráter de urgência se eles forem pequenos. Já as Empresas 03 e 04 apresentam maior dificuldade para atender aos pedidos urgentes.

Como recomendações, na armazenagem, de acordo com Moura (2008), deve ser realizado o agrupamento de itens conforme a popularidade, 
tamanho e características. Os itens de maior movimentação devem ficar localizados mais perto da expedição.

A utilização de estantes otimiza os espaços de armazenagem e possibilita um melhor aproveitamento de espaço. A indicação dos espaços de armazenagem e corredores auxilia no fluxo das atividades e facilita a localização dos itens (MOURA, 2008).

Moura (2008) também sugere a emissão de listas para a separação dos produtos e, na medida do possível, estabelecer processos de separação que não necessitem de conferências, além da medição de desempenho na separação (COSTA; MACADA, 2009).

\section{BLOCO EXPEDIÇÃO}

A atividade de Expedição é considerada a última atividade da logística interna e é responsável por colocar os produtos à disposição dos consumidores (MOURA, 2008).

Figura 8 - Pontuação Geral Bloco Expedição

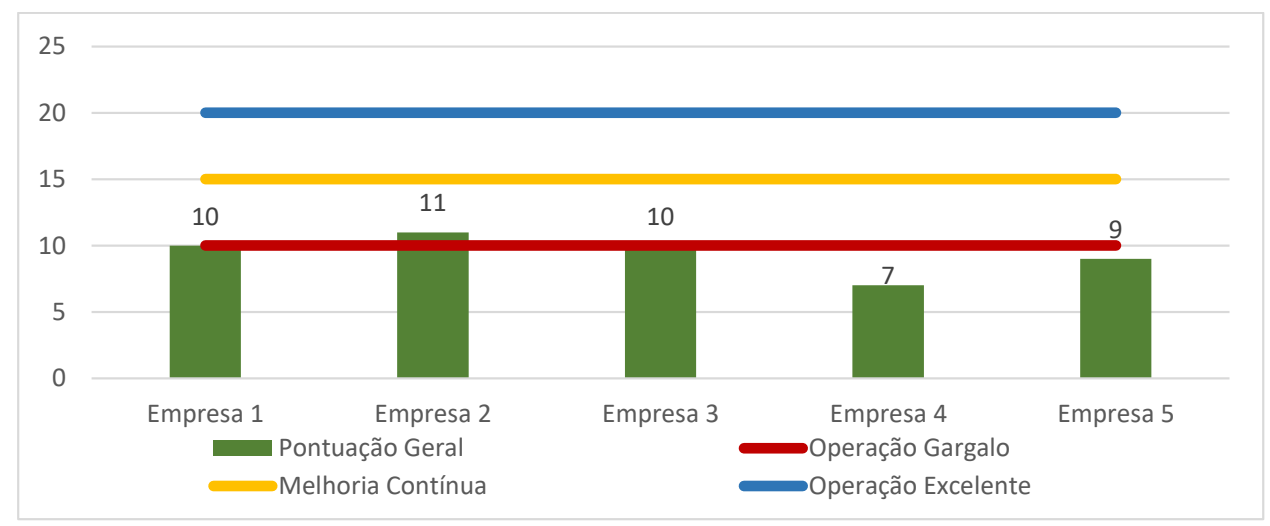

Fonte: Dados da Pesquisa.

A Expedição é uma atividade crítica nas Empresas 04 e 05. Ela merece um redesenho no processo para não comprometer a logística interna e, principalmente, a imagem das empresas perante os clientes. Já para as Empresas 01, 02 e 03, a atividade precisa de melhorias contínuas para atingir o nível de excelência. 
A documentação é simples e adequada em todas as empresas. Nesse sentido, é possível atender rapidamente aos pedidos urgentes, mas não são utilizados códigos de barras na expedição.

Moura (2008) sugere para a expedição o controle das rotas, a verificação dos históricos de reclamação dos clientes, o planejamento dos métodos de carregamento e a definição de métodos rápidos e ágeis para a emissão da documentação de expedição. $O$ autor sugere, ainda, a máxima utilização de equipamentos de movimentação que permitam o mínimo de manipulação possível.

\section{CONSIDERAÇÕES FINAIS}

De maneira geral, todas as vinícolas apresentaram deficiências em termos de logística interna, passando pela falta de planejamento, de objetivos, de metas e de indicadores. As atividades logísticas estão dispostas nas empresas, conforme apresentado na pesquisa, porém elas necessitam de alinhamento, redesenho e reestruturação. A estruturação da logística interna será primordial para atender a uma maior demanda que se projeta em decorrência da IG, pois o aumento nos volumes de venda implica em maiores volumes de compra e, consequentemente, gera maiores fluxos no recebimento, na movimentação e na expedição. Outro reflexo da estruturação da logística interna está no provimento de melhorias nos níveis de atendimento aos clientes e na redução dos custos logísticos.

Os resultados apresentados demonstram que a gestão das vinícolas não está diretamente relacionada ao tamanho e ao tempo de constituição das vinícolas, haja vista que a vinícola com maior tempo de fundação não é, necessariamente, a empresa que apresenta a maior produção, tampouco apresenta as melhores pontuações. As características da gestão dessas empresas com caráter familiar fazem com que os resultados não sejam necessariamente os mesmos, mesmo se o instrumento de pesquisa fosse aplicado em empresas com o mesmo porte e características semelhantes. Os próprios resultados desta pesquisa confirmam esse aspecto. Cada uma das vinícolas pesquisadas apresenta características e formas de organização da logística interna próprias, as quais são condizentes e adequadas ao seu porte e histórico.

No tocante ao desenvolvimento socioeconômico das vinícolas, a presente pesquisa pode contribuir de maneira significativa, destacando os pontos 
fracos da gestão da logística e da cadeia de suprimentos de cada organização. A Indicação Geográfica, no médio prazo, tende a causar impacto nos volumes produzidos e vendidos e, conforme citado anteriormente, será necessário adequar as estruturas logísticas atuais para atender à futura demanda. É importante destacar que o aumento na demanda causa impacto diretamente no desenvolvimento da região, em setores de serviços como gastronomia, turismo e enoturismo e no comércio como um todo.

As limitações da pesquisa perpassam a extensão do instrumento de pesquisa, que necessitou de um investimento de tempo de cada entrevistado, bem como a complexidade dos termos. Essa complexidade dos termos exigiu que o pesquisador esclarecesse as dúvidas dos entrevistados e adaptasse as questões para o seu entendimento. A quantidade limitada de estudos publicados, relacionados ao tema logística interna em organizações agrícolas, como se observou na revisão de literatura, foi outro fator limitador desta pesquisa.

Como estudos futuros, sugere-se a adaptação do instrumento de pesquisa de Moura (2008) para o contexto de pequenas empresas e posterior aplicação novamente de todo o novo instrumento, incluindo a comparação da logística interna das vinícolas dos Vales da Uva Goethe com outras vinícolas que têm contexto semelhante, pequenas empresas e as pertencentes às IGs, bem como a ampliação do estudo para os demais membros da cadeia de suprimentos.

\section{REFERÊNCIAS BIBLIOGRÁFICAS}

ASSOCIAÇÃO DE PRODUTORES DA UVA E DO VINHO GOETHE - PROGOETHE. Histórico PROGOETHE. Sem data de publicação [on-line]. Disponível em: <http://www.progoethe.com.br/>. Acesso em: 20 set. 2016.

BALLOU, R. H. Gerenciamento da cadeia de suprimentos/logística empresarial. 5. ed. Porto Alegre: Bookman, 2006.

BOWERSOX, D. J.; CLOSS, D.; COOPER, M. B. Gestão Logística de Cadeia de Suprimentos. Porto Alegre: Bookman, 2006.

BOWERSOX, D. J. et al. Logistical Excellence: It's not Business as Usual. Burlington/U.S.A.: Digital Press, 1992. 246 p. 
BRONZO, M. Relacionamentos colaborativos em redes de suprimentos. Rev. Adm. Empres. Rio de Janeiro, v. 44, n. spe, p.61-73, 2004. Disponível em: <http:// dx.doi.org/10.1590/S0034-75902004000500005>. Acesso em: 22 ago. 2016.

CHING, H. Y. Gestão de estoques na cadeia de logística integrada: Supply chain. 3. ed. São Paulo: Atlas, 2007.

CHOPRA, S.; MEINDL, P. Gestão da cadeia de Suprimentos: Estratégia, Planejamento e Operações. 4. ed. São Paulo: Pearson, 2011.

CHRISTOPHER, M. A logística do Marketing: Otimizando processos para aproximar fornecedores e consumidores. São Paulo: Futura, 1999.

COSTA, J. C.; MACADA, A. C. G. Gestão da informação interorganizacional na cadeia de suprimentos automotiva. RAE electron., Rio de Janeiro, v. 8, n. 2, 2009. ISSN 1676-5648. Disponível em: <http://dx.doi.org/10.1590/S167656482009000200005>. Acesso em: 25 ago. 2016.

FIGUEIREDO, K.; ARKADER, R. Da distribuição física ao supply chain management. In: FLEURY, P. F.; WANKE, P.; FIGUEIREDO, K. F. (Orgs.). Logística empresarial: a perspectiva brasileira. São Paulo: Atlas, 2000, p. 49-55.

FIGUEIREDO, K.; ARKADER, R. Da distribuição física ao supply chain management: o pensamento, o ensino e as necessidades de capacitação em logística. Rio de Janeiro: Ed. UFRJ, 2011.

FLEURY, P. F. Conceito de logística integrada e supply chain management. In: FLEURY, P. F.; WANKE, P.; FIGUEIREDO, K. F. (Orgs.). Logística empresarial: a perspectiva brasileira. São Paulo: Atlas, 2000, p. 27-38.

GIBSON, B. J.; MENTZER, J. T.; COOK, R. L. Supply Chain Management: the pursuit of a concensus definition. Journal of Business Logistics, v. 26, n. 2, p. 17-25, 2005.

GOMES, C. F. S.; RIBEIRO, P. C. C. Gestão da cadeia de suprimentos integrada à tecnologia da informação. São Paulo: Thomson, 2004.

GUARNIERI, P. et al. WMS - Warehouse Management System: adaptação proposta para o gerenciamento da logística reversa. Production, São Paulo, v. 16, n. 1, p. 126-139, abr. 2006. Disponível em: <http://dx.doi.org/10.1590/S010365132006000100011>. Acesso em: 13 ago. 2016.

KOBAYASHI, S. Renovação da logística: como definir estratégias de distribuição física global. São Paulo: Atlas, 2000. 
LAMBERT, D. M.; STOCK, J. R.; ELLRAM, L. M. Fundamentals of logistics management. Boston/U.S.A.: Irwin/McGraw-Hill, 1998.

LELIS, E. C.; SIMON, A. T. Gestão do relacionamento em uma indústria de peças plásticas da cadeia automotiva. Gest. Prod., Rio de Janeiro, v. 20, n. 4, p. 889-911, 2013. Disponível em:<http://dx.doi.org/10.1590/S0104-530X2013000400010>. Acesso em: 13 set. 2016.

MAESTRELLI, S. R. Do parreiral à taça: o vinho através da história. Urussanga: EPAGRI, 2011.

MORAIS, R. R. Logística Empresarial. Curitiba: Intersaberes, 2015.

MOURA, R. A. Check sua logística interna. São Paulo: IMAM, 2008.

NOVAES, A. G. Logística e gerenciamento da cadeia de distribuição: estratégia, operação e avaliação. Rio de Janeiro: Campus, 2001.

OJALA, L. M.; SEPPÄLÄ, T. A.; VAFIDIS, D. Using the 21st century benchmarking tool in Europe. In: Annual Conference of the Council of Logistics Management. Proceedings... Illinois: Council of Logistics Management, 2000, v. 1, p. 427-438.

PARDINI, D.; MATUCK, P. de J. P. Mudanças nas práticas organizacionais com a implementação do programa de gerenciamento da cadeia de suprimentos (GCS) em uma multinacional do setor siderúrgico. JISTEM USP, São Paulo, v. 9, n. 1, p. 147-170, 2012. Disponível em: <http://dx.doi.org/10.4301/S1807$17752012000100008>$. Acesso em: 19 set. 2016.

POZO, H. Administração de recursos materiais e patrimoniais. São Paulo: Atlas, 2002.

ROMEIRO, V. M. B. Gestão da pequena unidade de produção familiar de citros: Uma análise dos fatores influentes no sucesso do empreendimento do ponto de vista dos produtores de Bebedouro (SP). 2002. 242 f. Dissertação (Mestrado em Engenharia de Produção) - Escola de Engenharia de São Carlos, Universidade de São Paulo, São Paulo, 2002.

SCHUCK, M. R. et al. Identificação molecular da uva Goethe de Urussanga - SC por marcadores microssatélites. Rev. Bras. Frutic., Jaboticabal, v. 32, n. 3, p. 825831, set. 2010.

TAVARES, M. C. Gestão estratégica. 2. ed. São Paulo: Atlas, 2005.

VELLOSO, C. Q. Indicação Geográfica e desenvolvimento territorial sustentável: a atuação dos atores sociais nas dinâmicas de desenvolvimento territorial a par- 
tir da ligação do produto ao território (um estudo de caso em Urussanga, SC). 2008. 168 f. Dissertação (Mestrado em Agroecossistemas) - Centro de Ciências Agrárias, Universidade Federal de Santa Catarina, Florianópolis, 2008.

WANKE, P. Gestão de Estoque na Cadeia de Suprimentos: Decisões e Modelos Quantitativos. São Paulo: Atlas, 2003.

ZANQUETTO FILHO, H.; FEARNE, A.; PIZZOLATO, N. D. Gerenciamento da cadeia de abastecimento de hortifrutigranjeiros frescos: uma pesquisa exploratória no Reino Unido. Rev. Adm. Contemp., v. 10, n. 4, p.71-92, 2006. Disponível em: <http://dx.doi.org/10.1590/S1415-65552006000400004>. Acesso em: 14 ago. 2016. 